\title{
Effects of different product phases in aluminum dust detonation modeling
}

\author{
TENG HongHui* \& JIANG ZongLin \\ State Key Lab of High Temperature Gas Dynamics, Institute of Mechanics, Chinese Academy of Sciences, Beijing 100190, China
}

Received March 15, 2013; accepted June 17, 2013; published online September 5, 2013

\begin{abstract}
Modeling aluminum ( $\mathrm{Al})$ dust detonation is difficult due to uncertainties in the product species and fractions. Recent experiments indicate both gaseous and solid alumina may appear in the detonation product, but only the gaseous one was considered before. To resolve this drawback, we study the effects of different product phases on the detonation parameters with the hybrid combustion model proposed recently. Numerical results demonstrate that the assumption of gaseous product induces high velocity and pressure, while the assumption of solid product induces low velocity and pressure. To clarify how close-to-experiment results have been obtained with one phase assumption, we revisit previous studies and analyze the models. The inconsistency between the product phase and heat release is found, and then one model with variable heat release dependent on the product phase is proposed. Then simulations with both the gaseous and solid products are carried out, and results reveal the necessity of establishing a relationship between the heat release and reaction products.
\end{abstract}

detonation, aluminum, multiphase

PACS number(s): 47.40.Rs, 82.40.Fp, 82.33.Vx

Citation: Teng H H, Jiang Z L. Effects of different product phases in aluminum dust detonation modeling. Sci China-Phys Mech Astron, 2013, 56: 2178-2185, doi: $10.1007 / \mathrm{s} 11433-013-5268-1$

\section{Nomenclature}

$C=$ mole concentration, $\mathrm{mol} / \mathrm{m}^{3}$

$C_{d}=$ drag coefficient

$c_{p}=$ heat capacity, $\mathrm{J} /(\mathrm{mol} \cdot \mathrm{K})$

$d_{p}=$ particle diameter, $\mathrm{m}$

$E=$ specific total energy, $\mathrm{J} / \mathrm{kg}$

$e=$ specific internal energy, $\mathrm{J} / \mathrm{kg}$

$E_{a}=$ activation energy, $\mathrm{J} / \mathrm{mol}$

$f_{x}=$ rate of momentum transfer, $\mathrm{N} / \mathrm{m}^{3}$

$f r=$ fraction of product phase

$J_{i}=$ rate of mass transfer, $\mathrm{kg} /\left(\mathrm{m}^{3} \cdot \mathrm{s}\right)$

$K=$ diffusion reaction coefficient, $\mathrm{s} / \mathrm{m}^{2}$

$k_{d}=$ rate coefficient of diffusion reaction, $\mathrm{kg} \cdot \mathrm{m} /(\mathrm{mol} \cdot \mathrm{s})$

$k_{s}=$ rate coefficient of kinetic reaction, $\mathrm{kg} \cdot \mathrm{m} /(\mathrm{mol} \cdot \mathrm{s})$

$k_{0}=$ kinetic reaction coefficient, $\mathrm{kg} \cdot \mathrm{m} /(\mathrm{mol} \cdot \mathrm{s})$

*Corresponding author (email: hhteng@imech.ac.cn)
$L_{b}=\mathrm{Al}$ boiling latent heat, $\mathrm{J} / \mathrm{mol}$

$L_{m}=\mathrm{Al}$ melting latent heat, $\mathrm{J} / \mathrm{mol}$

$N u=$ Nusselt Number

$n_{i}=$ particle number density, $1 / \mathrm{m}^{3}$

$P r=$ Prandtl number

$Q_{d}=$ rate of heat transfer, $\mathrm{J} /\left(\mathrm{m}^{3} \cdot \mathrm{s}\right)$

$R e_{s}=$ two-phase Reynolds number

$t=$ time, $\mathrm{s}$

$T=$ gas temperature, $\mathrm{K}$

$T_{p}=$ particle temperature, $\mathrm{K}$

$u=$ gas velocity, $\mathrm{m} / \mathrm{s}$

$u_{p}=$ particle velocity, $\mathrm{m} / \mathrm{s}$

$W_{i}=$ molecular weight, $\mathrm{g} / \mathrm{mol}$

$x=$ distance, $\mathrm{m}$

$\lambda=$ thermal conductivity of gas, $\mathrm{W} /(\mathrm{m} \cdot \mathrm{K})$

$\sigma=$ bulk density of particle, $\mathrm{kg} / \mathrm{m}^{3}$

$\mu=$ dynamic viscosity coefficient $\mathrm{kg} /(\mathrm{m} \cdot \mathrm{s})$ 
$v_{i}=$ stoichiometric coefficient

$\rho=$ gas or particle density, $\mathrm{kg} / \mathrm{m}^{3}$

\section{Subscripts}

$g=$ gas-phase index

oxi= index for oxidizing gases

$p=$ particle-phase index

$\underline{\mathrm{s}}=$ index for particle surface

$0=$ initial state

\section{Introduction}

Detonation waves are waves of supersonic combustion induced by strong coupling shock and heat release. Detonation research has attracted much attention in recent years owing to its potential applications in hypersonic propulsion $[1,2]$. Aluminum (Al) particle detonation is a type of dust detonation, and its research is important in the prevention of industrial explosions [3]. Tulis and Selman [4] studied Al dust detonations for flake and spherical particles and found out that this kind of detonation is very sensitive to the specific area. Zhang et al. [5] investigated transverse waves in dusty detonations and calculated, using a detonation model, the minimum tube diameter for generating detonation. Flame acceleration and deflagration to detonation transition in the $\mathrm{Al}$ suspended mixtures have been studied experimentally [6-8]. Although the experimental results provide a research basis, information available from the experimental results is limited. Multi-phase combustion occurring in high-speed flow is very complex because it involves both chemical and gasdynamics phenomena. Thus, theoretical and numerical investigations are necessary to study Al dust detonations. Fedorov et al. [9] proposed a non-equilibrium model which can be used in both one-dimensional and two-dimensional cellular detonations. Papalexandris [10,11] studied the effects of particle, which could be either combustible or inert, to ascertain the structure and stability of dust detonations. Benkiewicz and Hayashi $[12,13]$ studied cellular structures and discussed the influence of particle diameters with an improved combustion model, which is proposed by controlling the combustion temperature.

According to the Glassman criterion [14], the combustion of Al dust should be diffusion- controlled, which is the basis of aforementioned studies. However, the assumption of diffusion-controlled combustion is questionable according to recent experimental results. Lynch et al. [15] demonstrated that the combustion time of particles, whose diameters are less than $10 \mu \mathrm{m}$, would be dependent on pressure and oxide mole fractions. Furthermore, if the particle diameter is of nanometer scale, the combustion becomes kinetics-controlled from diffusion-controlled $[16,17]$. Tanguay et al. $[18,19]$ found that even for a particle on the scale of 100 $\mu \mathrm{m}, \mathrm{Al}$ particle combustion is kinetics-controlled due to strong convection induced by detonations. To include the experimental progress, Zhang et al. [20] proposed an im- proved hybrid combustion model, which considers not only the diffusion-controlled but also kinetics-controlled combustion. Briand et al. [21] used this model for cellular detonation simulations, and they compared results with those obtained with the classic diffusion model. Teng and Jiang [22] studied the effect of realistic heat capacities used for the Al particle internal energy, and improved numerical results by introducing heat capacities that varied with the temperature.

The hybrid model has advanced considerably Al dust detonation modeling. Meanwhile, the inclusion of both kinetics- and diffusion-controlled combustion introduces unresolved problems. In the diffusion-controlled model, gaseous alumina $\mathrm{Al}_{2} \mathrm{O}_{3}(\mathrm{~g})$ is widely used. In the hybrid model, solid alumina $\mathrm{Al}_{2} \mathrm{O}_{3}(\mathrm{~s})$ is used in the initial paper, while gaseous alumina $\mathrm{Al}_{2} \mathrm{O}_{3}(\mathrm{~g})$ is also used in the later work [21]. Generally, kinetics-controlled combustion produces solid alumina $\mathrm{Al}_{2} \mathrm{O}_{3}(\mathrm{~s})$, while the diffusion-controlled combustion produces gaseous alumina $\mathrm{Al}_{2} \mathrm{O}_{3}(\mathrm{~g})$. Therefore, both of gaseous and solid products should be used with the hybrid model together. Medvedev et al. [23] proposed one detonation model considering both gaseous and condensed products, and studied the detonation propagation theoretically. However, that model derives from a one-velocity and onetemperature approximation, which brings much uncertainty. Now effects of different product phases on the detonation parameters are still unclear. In this paper, both $\mathrm{Al}_{2} \mathrm{O}_{3}(\mathrm{~s})$ and $\mathrm{Al}_{2} \mathrm{O}_{3}(\mathrm{~g})$ are used in $\mathrm{Al}$ dust detonation simulation and how the product phase affects dust detonation is studied. Furthermore, by revisiting previous models, a variable heat release model dependent on the product phase is proposed and discussed.

\section{Mathematical model and numerical method}

Because $\mathrm{Al}$ density is third-orders higher than gas density, volume fraction of the particle is not considered. Furthermore, the particle-particle interactions and viscous terms are also neglected according to previous research [9-13]. Governing equations of the gas phase can be written as:

$$
\frac{\partial U_{g}}{\partial t}+\frac{\partial F_{g}}{\partial x}=S_{g}+H_{g},
$$

where $S_{g}$ is the source term array induced by the chemical reaction, and $H_{g}$ is the source term array induced by the gas-particle interaction. Detailed expressions are written as:

$$
\begin{gathered}
U_{g}=\left[\begin{array}{lllll}
\rho_{1} & \cdots & \rho_{n} & \rho u & \rho E
\end{array}\right]^{\mathrm{T}}, \\
F_{g}=\left[\begin{array}{llllll}
\rho_{1} u & \cdots & \rho_{n} u & \rho u^{2}+p & (\rho E+p) u
\end{array}\right]^{\mathrm{T}}, \\
S_{g}=\left[\begin{array}{lllll}
\dot{\omega}_{1} & \cdots & \dot{\omega}_{n} & 0 & 0
\end{array}\right]^{\mathrm{T}},
\end{gathered}
$$




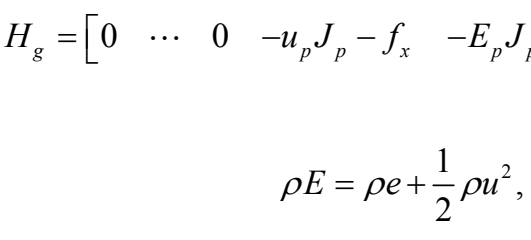

$$
\begin{aligned}
& p=\sum_{i=1}^{n} \rho_{i} R T / w_{i}, \\
& J_{p}=\sum_{i=1}^{m} J_{i},
\end{aligned}
$$

where $E_{p}$ is the total energy of the solid particle formed by the mass exchange between the solid and the gas; $f_{x}$ is the force between the solid particle and the gas; $Q_{d}$ is the heat conduction between the solid particle and the gas; $q_{p}$ is the heat release induced by the solid particle combustion.

Governing equations of the particle phase can be written as:

$$
\begin{aligned}
& \frac{\partial U_{p}}{\partial t}+\frac{\partial F_{p}}{\partial x}=S_{p}+H_{p} \\
& U_{p}=\left[\begin{array}{llllllll}
\sigma_{1} & \cdots & \sigma_{m} & \sigma u_{p} & \sigma E_{p} & n_{1} & \cdots & n_{m}
\end{array}\right]^{\mathrm{T}}, \\
& F_{p}=\left[\begin{array}{llllllll}
\sigma_{1} u_{p} & \cdots & \sigma_{m} u_{p} & \sigma u_{p}^{2} & \sigma E_{p} u_{p} & n_{1} u_{p} & \cdots & n_{m} u_{p}
\end{array}\right]^{\mathrm{T}} \text {, } \\
& S_{p}=\left[\begin{array}{llllllll}
J_{1} & \cdots & J_{n} & 0 & 0 & 0 & \cdots & 0
\end{array}\right]^{\mathrm{T}}, \\
& H_{p}=
\end{aligned}
$$

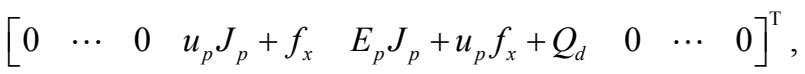

$$
\begin{aligned}
& \sigma E_{p}=\sigma e_{p}+\frac{1}{2} \sigma u_{p}^{2} \\
& \sigma=\sum_{i=1}^{m} \sigma_{i}
\end{aligned}
$$

The number density $n_{i}$ of each solid species can be calculated by $n_{i}=\frac{6 \sigma_{i}}{\pi \rho_{p i} d_{p i}^{3}}$. These two sets of governing equations are solved separately, and the interaction of the gas and particles is achieved through the array $H_{g}$ and $H_{p}$. By comparing two source arrays, the momentum and energy conservations still remain.

In completing the equations, the source terms needs to be modeled. The phase interaction force $f_{x}$ and heat conduction $Q_{d}$ can be written as:

$$
f_{x}=C_{d} \sum_{i=1}^{m} n_{i} \frac{\pi d_{p i}^{2}}{4} \rho\left(u-u_{p}\right) \sqrt{\left(u-u_{p}\right)^{2}} / 2,
$$

$$
Q_{d}=\sum_{i=1}^{m} n_{i} \pi d_{p i} N u \lambda\left(T-T_{p}\right),
$$

where

$$
\begin{gathered}
C_{d}=\frac{24}{\operatorname{Re}_{s}}\left(1+\frac{1}{6} \operatorname{Re}_{s}^{2 / 3}\right), \\
N u=2.0+0.459 \operatorname{Re}_{s}^{0.55} \operatorname{Pr}^{0.33}, \\
\operatorname{Re}_{s}=\frac{\rho \sqrt{\left(u-u_{p}\right)^{2}}}{\mu} \sum_{i=1}^{m} d_{p i} .
\end{gathered}
$$

The hybrid combustion model [20] is used to consider both the diffusion- and kinetic-controlled combustion. In this model the $\mathrm{Al}$ combustion rate is

$$
J_{1}=-n_{1} \pi d_{p 1}^{2} k_{1}=-n_{1} \pi d_{p 1}^{2} \frac{v_{1} W_{1}}{v_{o x i} W_{o x i}} k,
$$

where the total rate coefficient can be calculated

$$
k=k_{d}\left(C_{o x i}-C_{o x i, 0}\right), k=k_{s} C_{o x i, 0} .
$$

Form the above equations, one may get

$$
k=\frac{k_{d} k_{s}}{k_{d}+k_{s}} C_{o x i} .
$$

By combining eqs. (21) and (23), the total reaction rate can be calculated. For the diffusion-controlled combustion, Ranz-Marshall correlation [24] is used to model convective enhancement of mass transfer, and the reaction rate $k_{d}$ is

$$
k_{d}=\frac{v_{o x i} W_{o x i}}{v_{1} W_{1}} \frac{\rho_{p 1} d_{p 1}}{2 C_{\text {total }} K d_{p 1,0}^{2}}\left(1+0.276 \operatorname{Re}_{s}^{1 / 2} \operatorname{Pr}^{1 / 3}\right) .
$$

For the kinetics-controlled combustion, the reaction rate $k_{d}$ is

$$
k_{s}=k_{0} \mathrm{e}^{-E_{a} / R T} .
$$

In this paper, the constants used in the chemical model are the same as those in the previous paper [20], while $K=4 \times 10^{6} \mathrm{~s} / \mathrm{m}^{2}, k_{0}=1.2 \times 10^{3} \mathrm{~kg} \cdot \mathrm{m} / \mathrm{mol} \cdot \mathrm{s}, E_{a}=71.7 \mathrm{~kJ} / \mathrm{mol}$.

The shock-capturing method is dispersion controlled dissipation scheme [25], which is constructed to achieve second-order in space. In previous research with the hybrid model [20], the chemical reaction is simplified to

$$
\mathrm{Al}(\mathrm{s})+\frac{3}{4} \mathrm{O}_{2}(\mathrm{~g}) \rightarrow \frac{1}{2} \mathrm{Al}_{2} \mathrm{O}_{3}(\mathrm{~s}),
$$

while with the diffusion-controlled model, the chemical reaction is simplified to

$$
\mathrm{Al}(\mathrm{s})+\frac{3}{4} \mathrm{O}_{2}(\mathrm{~g}) \rightarrow \frac{1}{2} \mathrm{Al}_{2} \mathrm{O}_{3}(\mathrm{~g})
$$


In reality both of the reactions occur together, so this study will consider eqs. (26) and (27) in the simulation. Both $\mathrm{Al}_{2} \mathrm{O}_{3}$ (s) and $\mathrm{Al}_{2} \mathrm{O}_{3}(\mathrm{~g})$ are included to study the influence of different phases on the detonation parameters. Three kinds of gas species $\mathrm{O}_{2}(\mathrm{~g}), \mathrm{N}_{2}(\mathrm{~g})$ and $\mathrm{Al}_{2} \mathrm{O}_{3}(\mathrm{~g})$ are considered, whose properties change with temperature [26]. Two kinds of solid species, $\mathrm{Al}(\mathrm{s})$ and $\mathrm{Al}_{2} \mathrm{O}_{3}(\mathrm{~s})$ are included in the simulation.

\section{Numerical results and discussion}

\subsection{Effects of different product phases}

For examining the effects of product phase, Al dust detonation is first simulated with solid alumina $\mathrm{Al}_{2} \mathrm{O}_{3}(\mathrm{~s})$. According to previous experiments $[27,28]$, initial pressure is 2.5 atm and initial temperature is $300 \mathrm{~K}$. The average bulk density of Al particles, with the diameter $2 \mu \mathrm{m}$, is $1250 \mathrm{~g} / \mathrm{m}^{3}$ and there is no $\mathrm{Al}_{2} \mathrm{O}_{3}(\mathrm{~s})$ at the initial stage. Gaseous $\mathrm{O}_{2}(\mathrm{~g})$ and $\mathrm{N}_{2}(\mathrm{~g})$ have a ratio of mole concentrations 1:4 initially. Pressure profiles are shown in Figure 1, with the grid scale $0.5 \mathrm{~mm}$ and the calculation domain $6.0 \mathrm{~m}$ in length. The detonation is initiated by a small zone with high temperature and pressure near the left side of the domain. Self-sustained detonation occurs and a constant speed of detonation of $1828 \mathrm{~m} / \mathrm{s}$ is gradually reached. This result has been discussed and compared with experimental and numerical results before [22]. Although the velocity is higher than the experimental one, it is reasonable due to the simplification of the multi-phase combustion model.

If the product is assumed to be gaseous rather than solid, the dust detonation is significantly different, as shown in Figure 2. The maximum pressure is about 16.0 MPa, 64.0 times of pre-shock pressure, compared with $9.4 \mathrm{MPa}$ for the solid product. Additionally, the detonation velocity reaches approximately $2145 \mathrm{~m} / \mathrm{s}$, which is much higher than the velocity of $1828 \mathrm{~m} / \mathrm{s}$ for the solid product. For verifying the numerical results, a resolution test is carried out using different grid scales. The pressure profiles when the detonation arrives at $x=5.0 \mathrm{~m}$ are shown in Figure 3. The results are almost the same with different grids. The difference near the end of the expansion wave is due to the initiation zone, in which the high pressure and temperature are used. Because the reaction is very fast in the initiation zone, the grid resolution affects the results and induces the difference. How ever, the detonation velocities are very close, and the difference is hardly noticeable near the leading shock, which is the key region we are concerned with. The grid $0.5 \mathrm{~mm}$ ensures there are over 10 grids in the half reaction zone in this simulation. Usually this resolution is thought to be not enough to study the detonation dynamic such as instability, but it is accurate enough to simulate the velocity and pressure profiles we study in this paper. Therefore a grid 0.5 $\mathrm{mm}$ is used in the later cases.

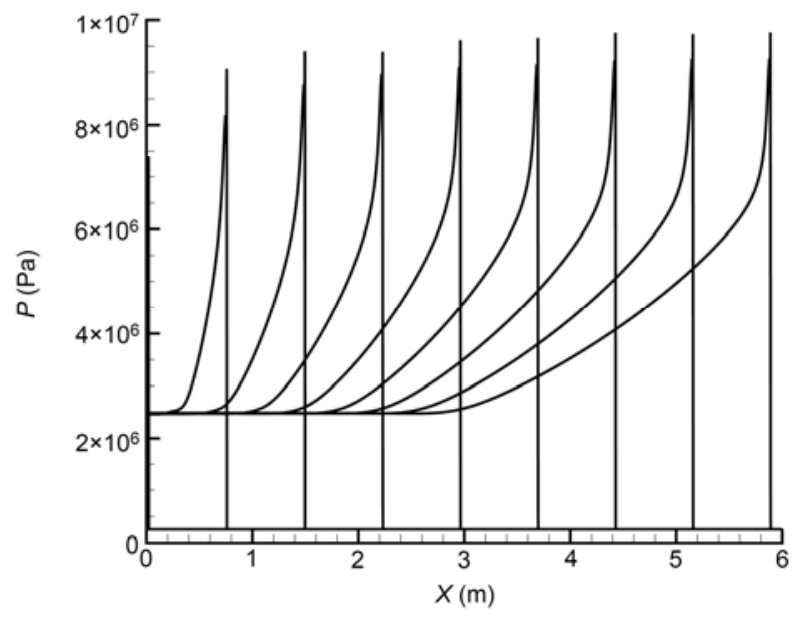

Figure 1 Pressure profiles of Al dust detonation with solid product.

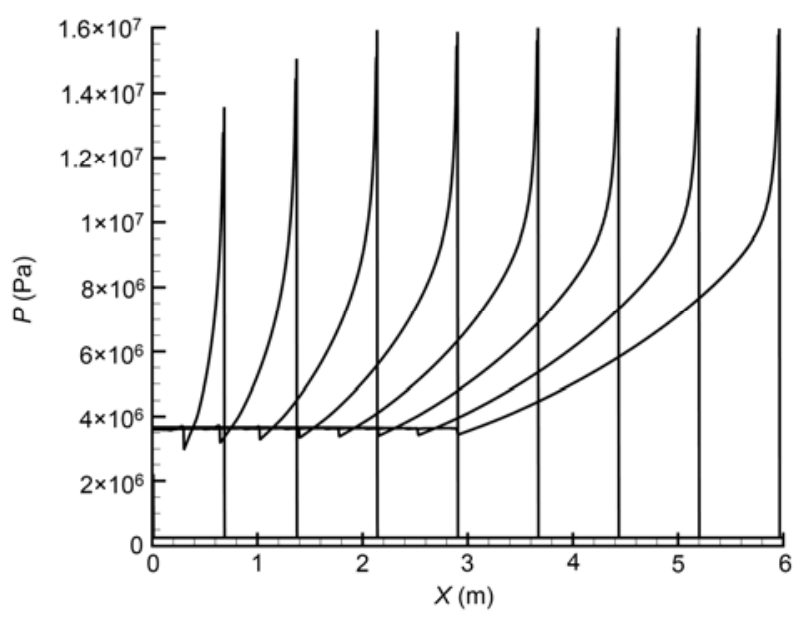

Figure 2 Pressure profiles of Al dust detonation with gaseous product.

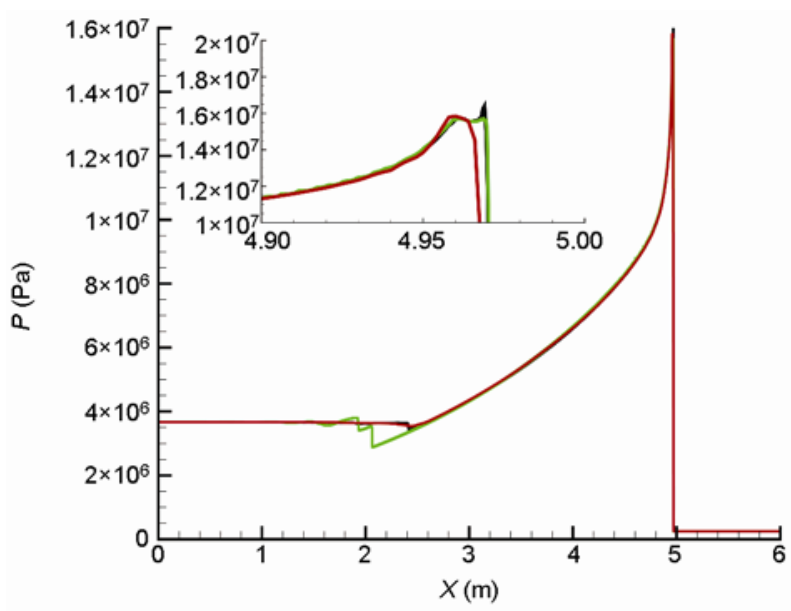

Figure 3 Resolution test of gaseous alumina results: red line $1.00 \mathrm{~mm}$, green line $0.50 \mathrm{~mm}$, black line $0.25 \mathrm{~mm}$.

Another case with both solid and gaseous alumina products is simulated. In this simulation, both the solid alumina 
and gaseous alumina take half parts in the detonation product. The realistic chemical reaction is

$$
\mathrm{Al}(\mathrm{s})+\frac{3}{4} \mathrm{O}_{2}(\mathrm{~g}) \rightarrow \frac{1}{4} \mathrm{Al}_{2} \mathrm{O}_{3}(\mathrm{~g})+\frac{1}{4} \mathrm{Al}_{2} \mathrm{O}_{3}(\mathrm{~s}) .
$$

The maximum pressure is about 13.0 $\mathrm{MPa}, 48.0$ times of pre-shock pressure, and the detonation velocity is about $2000 \mathrm{~m} / \mathrm{s}$. These results are between the results obtained from pure solid product and pure gaseous product.

Comparing the three results above, we draw preliminary conclusions about effects of the product phase on the detonation parameters. For given parameters, the assumption of gaseous product will induce higher pressure and velocity, while the assumption of solid product will induce weaker dust detonation. This is because the gaseous product contributes to the high pressure, and it expands to drive the detonation. The solid product, which does not contribute to the pressure, is driven by the gas-particle force. When the gaseous product is used in the simulation, there is strong detonation because more gas appears in the product, and the gas-particle force decreases at the same time. Therefore, there is strong detonation in the case of gaseous product, and weak detonation in the case of solid product.

\subsection{Revisiting previous models with gaseous product}

Although the effects of different product phases have been clarified, a new problem has emerged. When the gaseous product is introduced, the results deviate from, rather than approach experimental results. However, gaseous products are used in almost all previous models, even including the hybrid combustion model [21]. Moreover, most of our knowledge on $\mathrm{Al}$ dust detonation is from the diffusioncontrolled combustion model, in which the gaseous product is the standard choice. Therefore, we must revisit previous models and examine how the close-to-experiment results were simulated.

Generally speaking, there are no widely accepted Al dust detonation models. In gaseous detonation and combustion simulation, detailed and reduced mechanisms have been developed to allow researchers to work on the uniformed platform. Al multi-phase combustion, however, is complicated and even the domination of kinetics-controlled combustion has been found recently. Furthermore, experimental results are usually only the pressure and detonation velocity, and there is a lack of results for accurate combustion modeling. Thus, combustion is usually simplified into one-step irreversible heat release, with several empirical parameters. This introduces the uncertainty to the simulation results, but ensures the detonation velocity or pressure is close to experimental results.

Reviewing results published before, we find that they are mainly dependent on the heat release and the reaction rate. For example, the coefficients in the diffusion-controlled model $[29,30]$ are decided according to dusty detonation or combustion experiments. Pre-exponential factors in the kinetics-controlled model following the Arrhenius law [21] can be adjusted to match the detonation velocity. Besides changing the reaction coefficient, another way to get closeto-experiment results is by changing the heat release. In fact, the variation in chemical reaction coefficients has the same mechanism as the change in heat release, because both change the heat release before the CJ plane. Fedorov and Khmel [31] used variable heat release to make sure the detonation velocity remains the same as the experimental result for different particle concentrations. Benkiewicz and Hayashi [13] introduced the endothermic reaction

$$
\mathrm{Al}(\mathrm{s})+\frac{1}{2} \mathrm{O}_{2}(\mathrm{~g}) \rightarrow \mathrm{AlO}(\mathrm{g})
$$

in the post-shock combustion. This assumption is not arbitrary, but based on the fact that $\mathrm{AlO}(\mathrm{g})$ has been detected experimentally in the product. Because it is difficult to measure the $\mathrm{AlO}(\mathrm{g})$ quantity, coupling this reaction and the main exothermal reaction is difficult. The product temperature is chosen as the control parameter. When the temperature reaches above the alumina decomposition temperature, the exothermal reaction is replaced by the endothermic reaction, thus ensuring the product temperature is in a reasonable range.

Another way to change the heat release is to introduce latent heat [20,22], which is also used in this paper above. The results for different latent heat methods are shown in Table 1. If the latent heat is not considered as in other models, the pressure is $12.5 \mathrm{MPa}$ and the velocity is $2090 \mathrm{~m} / \mathrm{s}$, as indicated for case no. 1. If the latent heat, about 300 $\mathrm{kJ} / \mathrm{mol}$, is subtracted first, the resulting heat release is about $538 \mathrm{~kJ} / \mathrm{mol}$. The maximum pressure and velocity then become $8.5 \mathrm{MPa}$ and $1750 \mathrm{~m} / \mathrm{s}$, as indicated for case no. 3 . Because the original simulation gives the pressure 9.4 MPa, we can conclude that the real heat release is between the 838 and $538 \mathrm{~kJ} / \mathrm{mol}$, but closer to the later one.

Returning to the simulation results presented in sect. 3.1, note that the results for the gaseous alumina product are too high, which means the heat release is unsuitable. The heat release is set to approximately $800 \mathrm{~kJ} / \mathrm{mol}$, which is used in most previous research. Although close-to-experiment results can be obtained by changing the reaction rate, introducing the endothermic reaction or the latent heat is a more physical method. The endothermic reaction connects the heat release and product temperature, which is an important step in modeling $\mathrm{Al}$ dust detonation. In reality, the heat release is not constant, but varies as a function of local parameters. The heat release from the solid alumina formation

\begin{tabular}{ccc} 
Table 1 & \multicolumn{3}{c}{ Detonation parameters with different latent heat methods } \\
\hline Case No. & Pressure $(\mathrm{MPa})$ & Velocity $(\mathrm{m} / \mathrm{s})$ \\
\hline 1 & 12.5 & 2090 \\
2 & 9.4 & 1828 \\
3 & 8.5 & 1750 \\
\hline
\end{tabular}


is not the same as the release from the gaseous alumina formation. Previous models with gaseous alumina usually used the heat release from the solid alumina formation, approximately $800 \mathrm{~kJ} / \mathrm{mol}$. This induces the inconsistency, and the reaction rate thus needs to be adjusted to get closeto-experiment results. Furthermore, the constant heat release introduces other problems as reported in our previous research [22]. To model the Al dust detonation accurately requires abandoning the constant heat release.

\subsection{Heat release model dependent on the product phase}

The heat release is physically dependent on several parameters, especially when heterogeneous reactions are involved in the $\mathrm{Al}$ combustion. In the detailed mechanism used widely in gaseous detonations, the equilibrium parameters are prescribed to decide the final species, and the heat release can then be calculated from the enthalpy. However, this process is too complicated considering the multi-phase equilibrium, and it will obscure our main purpose. Here, one model with two heat release values is proposed as the primary step. The first value $Q_{s}$ is heat release from the solid alumina formation, and the second value $Q_{g}$ is heat release from the gaseous alumina formation. Referring to the results given in Table $1, Q_{s}$ is chosen to be $638 \mathrm{~kJ} / \mathrm{mol}$ without latent heat roughly. This value may produce results similar to those shown in Figure 1, and the latent heat release is not used to exclude unnecessary uncertainty. $Q_{g}$ is the heat release of $\mathrm{Al}_{2} \mathrm{O}_{3}(\mathrm{~g})$ formation and is set to be $273 \mathrm{~kJ} / \mathrm{mol}$, the heat of formation for standard state [26]. In this model, the fractions of the gaseous and solid products are prescribed, and the heat release is calculated according to the fractions, that is

$$
Q=f r_{s} \cdot Q_{s}+f r_{g} \cdot Q_{g}, f r_{s}+f r_{g}=1,
$$

where $f r_{s}$ is the fraction of solid product and $f r_{g}$ is the fraction of gaseous product. We stress here that our intention is not to develop an accurate model to simulate $\mathrm{Al}$ particle detonation, but to ascertain key factors to develop advanced Al detonation models. Therefore, these heat release values $Q_{s}$ and $Q_{g}$ are not exact, but certain values in a reasonable range. There are too many uncertainties in the current models, and in this study we focus on the choice of heat release related to the product phase.

The detonation wave with $f_{s}=0, f_{g}=1$, which corresponds to purely gaseous product, is simulated first and shown in Figure 4. The maximum pressure is $10.5 \mathrm{MPa}$ and the velocity is $1796 \mathrm{~m} / \mathrm{s}$. These results are close to the results shown in Figure 1, for only solid product. Indeed, this is the extreme case because the solid product is absent, but the results are much better than the results shown in Figure 2. The underlying reason is that the heat release $Q_{g}$, which corresponds to the formation heat of gaseous alumina, is consistent with the product phase. In most previous models, the heat release is approximately $800 \mathrm{~kJ} / \mathrm{mol}$, but the product is gaseous. We note that those models are inconsistent, although some close-to-experimental results can be produced.

Al dust detonation waves with various fractions of gaseous alumina are simulated, as shown in Figure 5. When the gaseous product ratio increases, the velocity decreases and the maximum pressure increases. This deviates from effects of different product phases, because the velocity and pressure change in the same manner in the case of single product phase. However, the velocity variation is less than $3 \%$, and the pressure variation is less than $8 \%$. These differences are not of the same order as the differences shown in Figures 1 and 2 . Thus it can be concluded that the detonation velocity and pressure are insensitive to the product phases, if the values of heat release are chosen properly.

\subsection{Discussion}

In previous research, $\mathrm{Al}$ combustion in dust detonation was

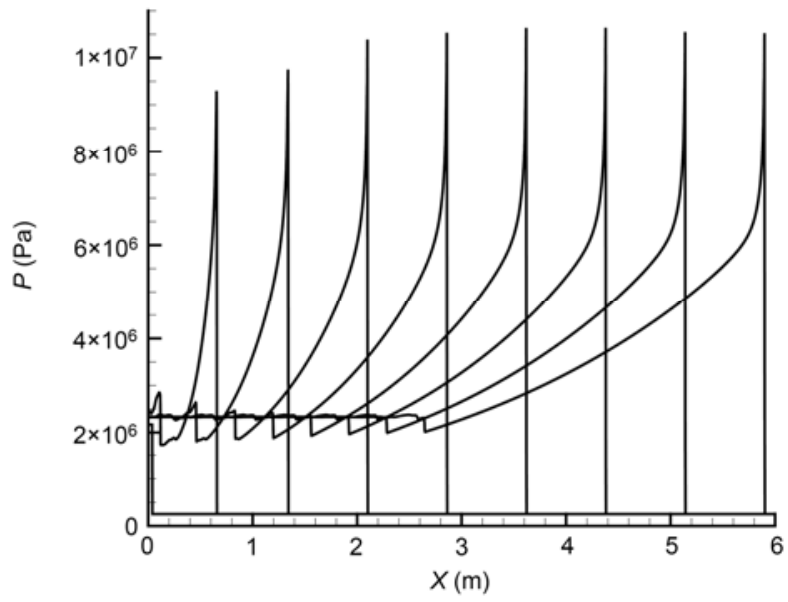

Figure 4 Pressure profiles of $\mathrm{Al}$ dust detonation with gaseous product and modified heat release.

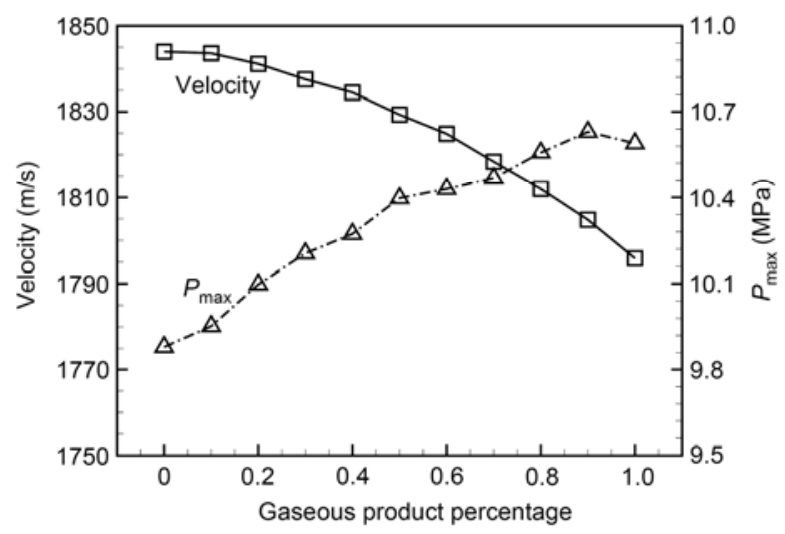

Figure 5 Detonation velocity and maximum pressure of Al dust detonation as a function of the gaseous product percentage. 
thought to be diffusion-controlled, like the combustion of a liquid droplet. However, more evidence of kinetics-controlled combustion was observed in recent experiments [15-18]. There are two factors inducing the combustion transition from diffusion-controlled to kinetics-controlled. One is the scale of Al particle, which is usually about several microns. The other is the strong convection, because the high-speed flow induced by the detonation can enhance the diffusion rate. Currently, the detailed mechanism of the multi-phase combustion is still not clear, and the simplified model has to be used in current research. In the simplified model, the most important parameter model is the heat release value, since it affects the detonation parameters significantly. The heat release used in previous models is usually questionable, and in particular, it is inconsistent with the product phase. Although close-to-experiment results can be obtained using several methods aforementioned, the detonation structure and dynamics may deviate from the reality, which will be potential obstacles in the further research.

We proposed a heat release model dependent on the product phase in this paper. The heat release in previous models has usually been fixed to be approximately 800 $\mathrm{kJ} / \mathrm{mol}$, which is the heat of combustion from $\mathrm{Al}(\mathrm{s})$ to $\mathrm{Al}_{2} \mathrm{O}_{3}(\mathrm{~s})$. This is inconsistent with the gaseous model, because the combustion heat will be much lower when gaseous alumina $\mathrm{Al}_{2} \mathrm{O}_{3}(\mathrm{~g})$ forms. In this model, the total heat release varies according to the product fractions. Simulation results demonstrate that the detonation velocity and pressure are affected by the fraction slightly, and the detonation is insensitive to the product phase. This is beneficial for the engineering simulation, because the species fractions in $\mathrm{Al}$ dust products are still unclear.

Physically, the proposed model reveals the necessity to establish the relationship between the heat release and reaction product. We introduce variable heat release by coupling gaseous and solid alumina formation heat. This sets up the connection between the product phase and heat release, which have been separated artificially before. Constant heat release, which is used in most previous models, may introduce several problems and should be abandoned.

\section{Conclusion}

Al dust detonation was simulated numerically to study the effects of product phases and the choice of heat release. Recent experiments indicate that there may be the diffusion-controlled combustion in Al dust detonation, and a hybrid combustion model is proposed on this basis. This demonstrates that both gaseous and solid products may appear in the detonation, but effects of different product phases on the detonation parameters have not yet been studied. Numerical results show that gaseous product will induce high velocity and pressure, while solid product will induce low velocity and pressure. To clarify how close-to-experiment results have been obtained with one phase assumption, we revisit previous studies and analyze the models. The inconsistency between the product phase and heat release is found and then one model with variable heat release dependent on the product phase is proposed. With this model, simulation results show both the detonation velocity and pressure are insensitive to the product phases, if the values of heat release are chosen properly. This reveals the necessity of establishing a relationship between the heat release and reaction products, which is unavoidable in high accuracy $\mathrm{Al}$ dust detonation models.

This work was supported by the National Natural Science Foundation of China (Grant No. 90916028).

1 Kailasanath K. Review of propulsion applications of detonation waves. AIAA J, 2000, 38: 1698-1708

2 Zhang X D, Fan B C, Gui M Y, et al. Cellular structure of detonation utilized in propulsion system. Sci China-Phys Mech Astron, 2012, 55: 1915-1924

3 Guo K K, Acharya R. Application of Turbulent and Multiphase Combustion. Hoboken: John Wiley \& Sons, Inc., 2012

4 Tulis A J, Selman J R. Detonation tube studies of aluminum particles dispersed in air. Symp (Int) Combust, 1982, 19: 655-663

5 Zhang F, Grönig H, van de Ven A. DDT and detonation waves in dust-air mixtures. Shock Waves, 2001, 11: 53-71

6 Chen Z, Fan B. Flame propagation through aluminum particle cloud in a combustion tube. J Loss Prev Proc, 2005, 18: 914-921

7 Liu Q M, Li X D, Bai C H. Deflagration to detonation in aluminum dust-air mixture under weak ignition condition. Combust Flame, 2009, 156: 914-921

8 Liu Q M, Bai C H, Jiang L, et al. Deflagration-to-detonation transition process for spherical aluminum dust/epoxypropane mist/air mixtures in a large-scale experimental tube. Sci China-Phys Mech Astron, 2011, 54: 533-541

9 Fedorov A V, Fomin V M, Khmel T A. Mathematical modeling of heterogeneous detonation in gas suspensions of aluminum and coaldust particles. Combust Explos Shock Waves, 2009, 45: 495-505

10 Papalexandris M V. Numerical simulation of detonations in mixtures of gases and solid particles. J Fluid Mech, 2004, 507: 95-142

11 Papalexandris M V. Influence of inert particles on the propagation of multidimensional detonation waves. Combust Flame, 2005, 141: 216-228

12 Benkiewicz K, Hayashi A K. One-dimensional parametric studies of an aluminum dust combustion model for numerical simulations of detonation waves. AIAA J, 2006, 44: 608-619

13 Benkiewicz K, Hayashi A K. Two-dimensional numerical simulations of multi-headed detonations in oxygen-aluminum mixtures using an adaptive mesh refinement. Shock Waves, 2003, 13: 385-402

14 Glassman I, Yetter R A. Combustion. 4th ed. Oxford: Elsevier, 2008

15 Lynch P, Krier H, Glumac N. A correlation for burn time of aluminum particles in the transition regime. Proc Combust Inst, 2009, 32: 1887-1893

16 Bazyn T, Krier H, Glumac N. Combustion of nanoaluminum at elevated pressure and temperature behind reflected shock waves. Combust Flame, 2006, 145: 703-713

17 Lynch P, Giovanni F, Krier H, et al. Gas-phase reaction in nanoaluminum combustion. Combust Sci Tech, 2010, 182: 842-857

18 Tanguay V. Combustion of Reactive Metal Particles in High-speed Flow of Detonation Products. Dissertation for Doctoral Degree. Montreal: McGill University, 2005

19 Tanguay V, Goroshin S, Higgins A J, et al. Aluminum particle combustion in high-speed detonation products. Combust Sci Tech, 2009, 
181: 670-693

20 Zhang F, Gerrard K, Ripley R C. Reaction mechanism of aluminum-particle-air detonation. J Propul Power, 2009, 25: 845-858

21 Briand A, Veyssiere B, Khasainov B A. Modelling of detonation cellular structure in aluminium suspensions. Shock Waves, 2012, 20: 521-529

22 Teng H, Jiang Z. Numerical simulation of one-dimensional aluminum particle-air detonation with realistic heat capacities. Combust Flame, 2013, 160: 463-472

23 Medvedev A E, Fedorov A V, Fomin V M. Description of ignition and combustion of gas mixtures with solid particles by methods of the mechanics of continuous media. Combust Explos Shock Waves, 1984, 20: 127-133

24 Crowe C T, Schwarzkopf J D, Sommerfeld M, et al. Multiphase Flows with Droplets and Particles. 2nd ed. Boca Raton: CRC Press, Taylor \& Francis Group, 2012

25 Jiang Z L. On dispersion-controlled principles for non-oscillatory shock capturing schemes. Acta Mech Sin, 2004, 20: 1-15

26 McBride B J, Zehe M J, Gordon S. NASA Glenn coefficients for calculating thermodynamic properties of individual species. NASA TP-2002-211556, 2002

27 Zhang F, Murray S B, Gerrard K B. Aluminum particles-air detonation at elevated pressures. Shock Waves, 2006, 15: 313-324

28 Zhang F. Detonation in reactive solid particle-gas flow. J Propul Power, 2006, 22: 1289-1309

29 Fedorov A V, Kratova Y V, Khmel T A. Shock and detonation wave diffraction at a sudden expansion in gas-particle mixtures. Shock Waves, 2008, 18: 281-290

30 Veyssiere B, Khasainov B A, Briand A. Investigation of detonation initiation in aluminum suspensions. Shock Waves, 2008, 18: 307-315

31 Fedorov A V, Khmel T A. Numerical simulation of formation of cellular heterogeneous detonation of aluminum particles in oxygen. Combust Explos Shock Waves, 2005, 41: 435-448 